\title{
Sistem Informasi Penjualan Online Berbasis Web pada Toko Sari Tani Tegal
}

\author{
Suharnawi ${ }^{1}$, Ramadhan Rakhmat Sani ${ }^{2}$, Wulan Puspita Loka ${ }^{2}$ \\ Program Studi Sistem Informasi - S1, Fakultas Ilmu Komputer, \\ Universitas Dian Nuswantoro \\ e-mail: 1'suharnawi@dsn.dinus.ac.id, ${ }^{2}$ ramadhan_rs@dsn.dinus.ac.id \\ ${ }^{2}$ wulanpuspitaloka@gmail.com
}

Diterima: 25 Juli 2020 ; Direvisi: 14 Oktober 2020; Disetujui : 14 Nopember 2020

\begin{abstract}
Abstrak
Toko Sari Tani Tegal adalah badan usaha yang bergerak di bidang penjualan pupuk dan obatobatan pertanian. Sistem penjualan barang yang digunakan saat ini masih dilakukan menggunakan sistem konvensional, yaitu pembeli harus datang langsung ke toko atau menelpon untuk melakukan pemesanan pupuk. E-Commerce mempunyai komponen penyebaran, pembelian, penjualan, pemasaran barang atau jasa menggunakan sistem elektronik seperti internet, televisi, atau jaringan komputer lainnya. Toko Sari Tani Tegal belum menggunakan e-commerce, sehingga kesulitan dalam menawarkan produk kepada konsumen yang berada di luar kota. Proses penjualan Toko Sari Tani Tegal hanya dilakukan apabila terdapat konsumen yang datang ke toko tersebut. Tujuan dari pembuatan sistem ini yaitu untuk membangun sistem informasi penjualan secara online berbasis web agar dapat diakses siapa saja, kapan saja dan dimana saja yang memudahkan transaksi penjualan. Metode yang digunakan dalam penelitian ini menggunakan metode Web Engineering yang mana memiliki beberapa tahapan sebagai berikut : Communication (Komunikasi), Planning (Perencanaan), Modelling (Pemodelan), Construction (Pembangunan) dan Deployment (Penyebaran). Dengan dibangunnya Web ini diharapkan dapat meningkatkan volume penjualan serta dapat memberikan informasi mengenai produk yang tersedia kepada pelanggan yang dapat diakses dari mana saja dengan cepat.
\end{abstract}

Kata kunci: sistem informasi, sistem penjualan, e-commerce, web engineering.

\begin{abstract}
Sari Tani Store Tegal is a business entity engaged in the sale of fertilizers and agricultural pharmaceuticals. The system for selling goods currently used is carried out using a conventional system, where buyers have to come directly to the shop or make a phone call to order fertilizer. E-Commerce has components for distributing, buying, selling, marketing goods or services using electronic systems such as the internet, television, or other computer networks. Toko Sari Tani Tegal has not used e-commerce, so it is difficult to offer products to consumers who are outside the city. The process of selling Sari Tani Tegal Shop is only carried out if there are consumers who come to the shop. The purpose of making this system is to build a web-based online sales information system so that it can be accessed by anyone, anytime and anywhere which facilitates sales transactions. The method used in this research uses the Web Engineering method which is in the following stages: Communication (Communication), Planning (Planning), Modeling (Modeling), Construction (Development) and Deployment (Spread). With the development of this Web, it is hoped that it can increase sales volume and can provide information about the products available to customers which can be accessed quickly from anywhere.
\end{abstract}


Keywords: information system, sales system, e-commerce, web engineering

\section{PENDAHULUAN}

Perkembangan sehubungan dengan teknologi dan informasi yang sangat pesat, sudah tentu banyak sektor kehidupan yang dituntut untuk menggunakannya. Salah satu bentuk bisnis yang sedang menjadi tren terbaru di waktu ini adalah e-commerce [1]. Indonesia yang terdiri dari banyak kepulauan dengan penduduk mayoritas sebagai petani tentu merupakan pangsa pasar yang besar. Sehingga menjadikan sektor pertanian yang turut diperhitungkan dalam kemajuan ekonomi Indonesia. Permintaan produk pertanian yang semakin meningkat membutuhkan keragaman produk dengan berbagai variasi, sehingga dapat menjadikan peluang yang lebih besar terhadap diversifikasi produk.

Toko Sari Tani Tegal yang berlokasi di Jalan Raya Sidapurna Desa Sidapurna Kabupaten Tegal adalah sebuah badan usaha yang bergerak di bidang pertanian dan menyediakan pupuk untuk dijual dipasaran. Proses bisnis yang ada pada Toko Sari Tani Tegal masih menggunakan cara konvesional yang mana pelanggan harus datang ke toko atau menelpon guna melakukan pemesanan pupuk. Pemesanan yang dilakukan melalui telpon mengakibatkan pegawai harus mencatat pesanan pelanggan dan mencari barang yang dibutuhkan oleh pelanggan. Berdasarkan data penjualan pada Toko Sari Tani, $80 \%$ pelanggan berasal dari wilayah kota Tegal. Sehingga hal tersebut mengakibatkan jangkauan penjualan pada Toko Sari Tani Tegal masih terbatas hanya di daerah tersebut. Penggunaan sistem yang masih konvensional juga mengakibatkan pelanggan yang terdapat di luar kota atau luar provinsi tidak dapat melakukan transaksi dengan mudah [2]. Untuk memenuhi besarnya tingkat permintaan produk pertanian di Indonesia, Toko Sari Tani Tegal ingin memperluas jangkauan penjualannya untuk mendapatkan pelanggan wilayah setempat ataupun luar daerah. Dengan hal tersebut maka juga dapat meningkatkan hasil penjualan pada Toko Sari Tani Tegal. Persaingan bisnis membuat perusahaan besar maupun perusahaan kecil bersaing dalam mengingkatkan mutu dan penjualannya.

Salah satu cara membantu permasalahan yang ada pada Toko Sari Tani yaitu dengan dibuatnya sistem informasi penjualan [3] yang dijalankan secara online berbasis web. Dengan pembuatan sistem yang berbasis web akan memudahkan pemilik dalam mengembangkan usahanya, mudah diakses oleh siapapun, dimanapun, dan kapanpun. Web Engineering merupakan suatu model rekayasa perangkat lunak yang digunakan untuk pengembangan aplikasi-aplikasi web yang berkualitas tinggi yang memiliki prinsip dan konsep yang mendasar dari rekayasa perangkat lunak (software engineering) [4]. Penggunaan metode Web Engineering ini cukup efektif sebagai paradigma dalam rekayasa software, karena mendapatkan aturan yang jelas yang disetujui oleh pelanggan sehingga dalam pembuatan perangkat lunak bisa dilakukan secara cepat [5]. Dalam penelitian [6] menggunakan metode Web Engineering hasil yang didapat yaitu memudahkan proses penjualan menjadi lebih mudah diakses kapan saja dan dimana saja dan sistem penjualan berbasis web, mempermudah konsumen dalam memperoleh informasi tentang detail produk dan harga barang serta dapat memudahkan dalam pengolahan manajemen data penjualan.

\section{METODE PENELITIAN}

Penelitian ini menggunakan sumber data yang didapat dari Toko Sari Tani Tegal. Metode pengumpulan data yang digunakan penelitian adalah data yang berasal dari studi pustaka, observasi, dan wawancara. Sedangkan dalam penelitian ini menggunakan metode pengembangan sistem dengan model web engineering [4]. 


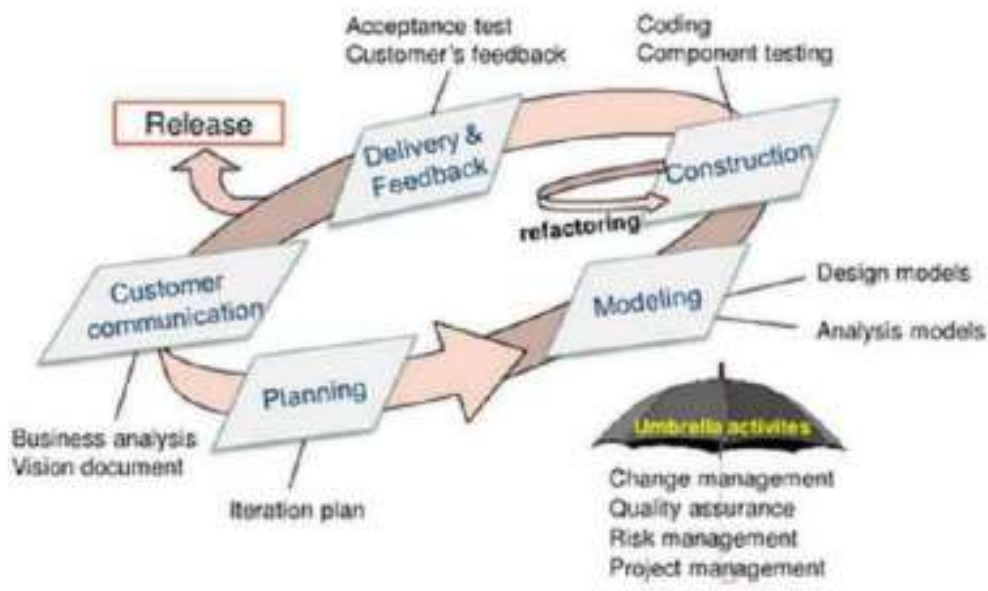

Gambar 1. Metode web engineering

berikut :

Pada gambar 1 diatas metode web engineering yang memiliki 5 tahapan proses sebagai

\section{Customer communication}

Tahapan customer cominication dilakukan dengan mendefinisikan hal-hal apa saja yang termuat pada aplikasi web penjualan online, misalnya pemakai web yang akan dibuat, perubahan potensial di lingkungan bisnis yang ada pada Toko Sari Tani Tegal maupun data-data yang dibutuhkan untuk pembuatan web penjualan online seperti data barang, data transaksi dan data pembayaran.

2. Planning

Tahap mengidentifikasi software dan hardware apa saja yang dibutuhkan, seperti spesifikasi komputer atau laptop yang digunakan, serta aplikasi yang dijalankan pada website penjualan online Toko Sari Tani Tegal.

3. Modeling

Tahap dimana analisa rekayasa software dengan mengembangkan desain model UML [7] seperti use case diagram, activity diagram, sequence diagram, class diagram yang akan digunakan untuk pembuatan website penjualan online pada Toko Sari Tani Tegal.

4. Construction

Pada hahapan ini menentukan alat-alat web engineering dan teknologi yang digunakan seperti dengan penggunaan bahasa pemnrograman php, dan MySQL sebgai databasenya dan nantinya diterapkan untuk membangun aplikasi yang dimodelkan sebagai contoh adalah interface web. Adapan pengujian yang dilakukan menggunakan black box testing dan white box testing

5. Deployment

Tahap ini dilakukan untuk mengkonfigurasi aplikasi website penjualan seacara online Toko Sari Tani dengan lingkungan pelaksanaan di Toko Sari Tani Tegal.

\section{HASIL DAN PEMBAHASAN}

\subsection{Communication}

Tahap komunikasi merupakan proses pengumpulan kebutuhan dari permasalahan yang ada pada Toko Sari Tani Tegal. Pada tahap ini mendefinisikan proses terkait apa saja yang akan dibuat di dalam sistem penjualan online.

1. Indentifikasi Masalah

Permasalahan yang terjadi pada Toko Sari Tani adalah jangkauan penjualan masih terbatas hanya di daerah tersebut. Penggunaan sistem yang masih konvensional juga 
mengakibatkan Toko Sari Tani tidak bisa menangani transaksi penjualan sampai ke luar kota atau provinsi.

2. Sistem yang diusulkan

Sistem yang diusulkan adalah sistem informasi penjualan online yang dapat dimanfaatkan untuk melakukan suatu transaksi penjualan dari mana saja dan kapan saja. Sehingga dapat memperluas jangkauan penjualan dan mempermudah pelanggan dalam melakukan transaksi pembelian tanpa menyita banyak waktu.

\subsection{Planning}

Pada tahapan ini dilakukan dengan mengidentifikasi software dan hardware apa saja yang digunakan untuk pembuatan sistem penjualan online.

\subsection{Modeling}

Tahap dimana analisa rekayasa software dengan mengembangkan desain model web yang akan digunakan untuk pembuatan website penjualan online pada Toko Sari TaniTegal.

\section{A. Usecase Diagram}

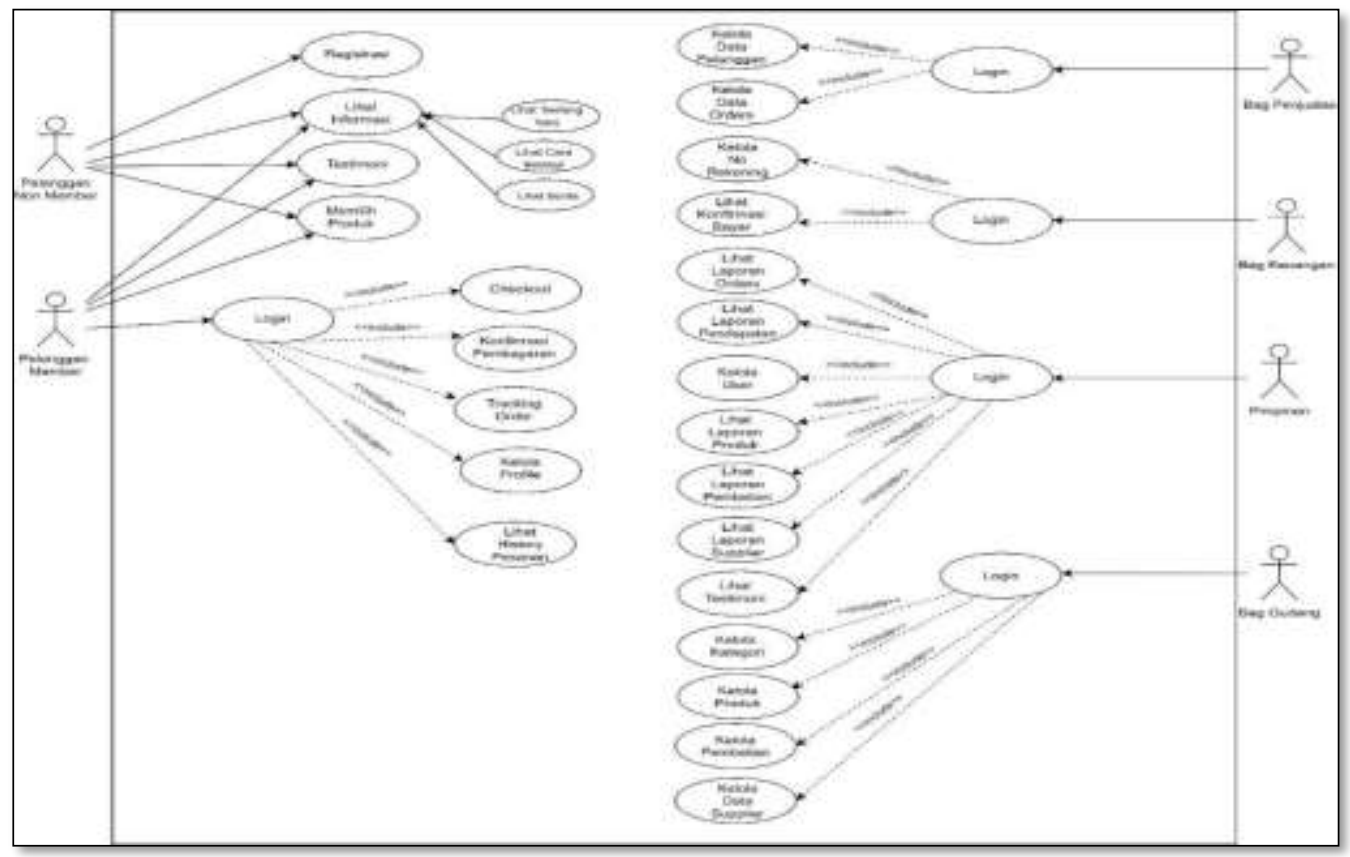

Gambar 2. Usecase Diagram

Sistem use case pada gambar 2 mempresentasikan sebuah interaksi yang dilakukan pada Toko Sari Tani Tegal antara aktor dengan sistem. Dimana penjelasan aktor sistem dan interaksi yang dilakukan yaitu pimpinan merupakah aktor dengan hak akses seperti melihat laporan produk, laporan order, laporan pembelian, laporan pendapatan, laporan supplier, dan kelola user yang ada di dalam sistem penjualan online, melihat testimoni. Bagian Penjualan merupakah aktor dengan hak akses seperti mengelola data pelanggan, mengelola data order. Bagian Keuangan merupakah aktor dengan hak akses seperti mengelola no rekening, mengecek konfirmasi pembayaran, melihat laporan pendapatan. Bagian Gudang merupakah aktor dengan hak akses seperti mengelola kategori, mengelola produk, mengelola pembelian, mengelola data supplier, melihat laporan pembelian, melihat laporan supplier. Pelanggan member merupakan aktor dalam sitem yang dapat melihat produk, melihat cara belanja, melihat keranjang, melihat testimoni, melihat 
informasi tentang toko serta dapat melakukan checkout dan tracking order. Pelanggan non member merupakan aktor dalam sistem yang dapat melakukan registrasi, melihat produk, melihat cara belanja, melihat keranjang, melihat testimoni, melihat informasi tentang toko.

\section{B. Class Diagram}

Class Diagram berikut pada gambar 3 menggambarkan keadaan /atribut suatu sistem yang ada pada Toko Sari Tani Tegal, serta layanan yang berisikan metode/fungsi untuk memanipulasi atribut. Class diagram juga menggambarkan tentang deskripsi dan struktur objek, class, dan package beserta hubungannya. Berikut merupakan Class Diagram dari sistem penjualan pada Toko Sari Tani Tegal :

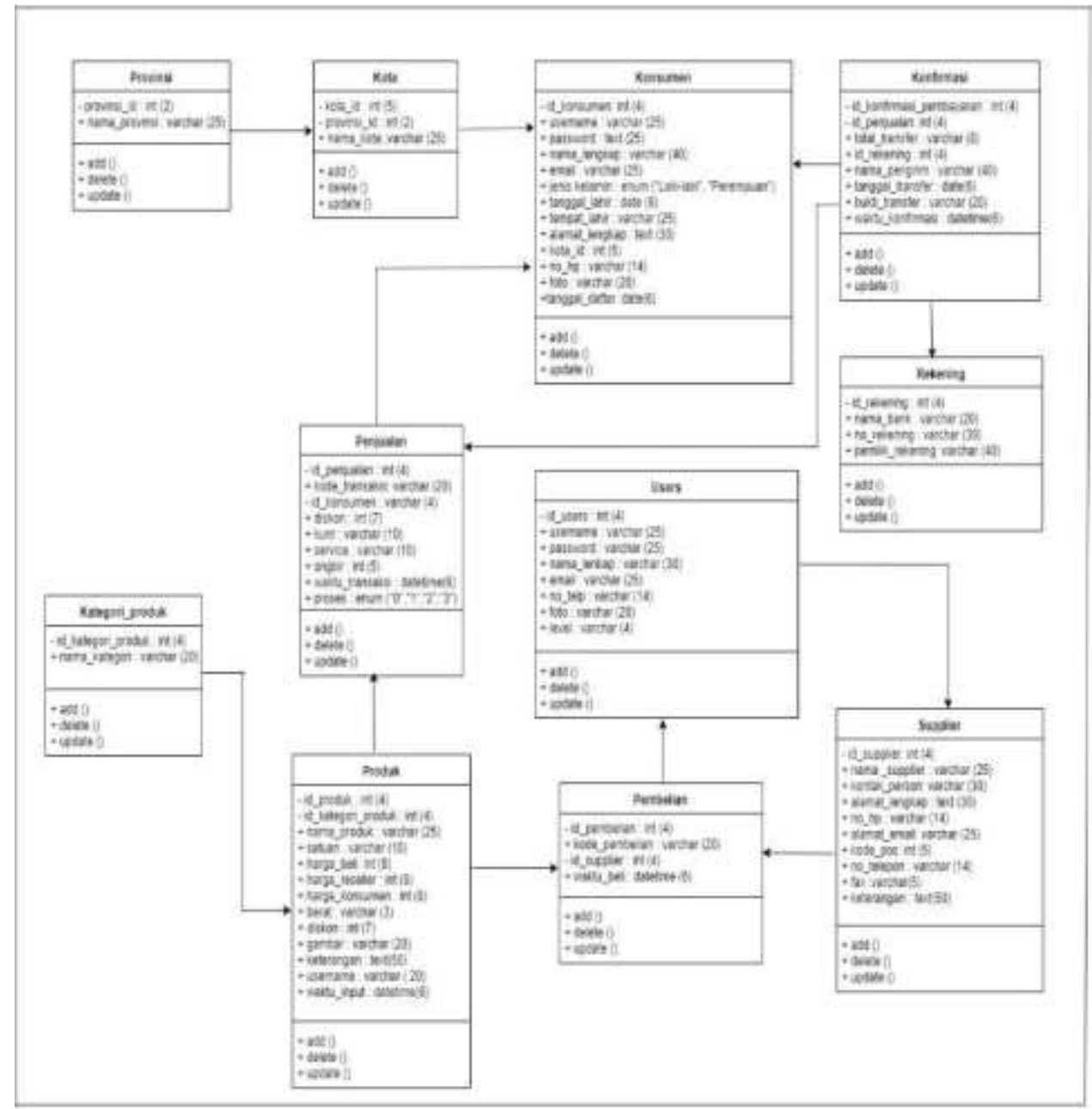

Gambar 3. Class Diagram

\subsection{Construction}

Pada Tahap ini menentukan alat-alat web engineering dan teknologi yang digunakan dalam membangun aplikasi yang sudah dimodelkan seperti interface web.

1. Perancangan Interface / Antar muka

Dalam perancangan interface / antar muka adalah menggambarkan secara detail sistem yang dirancang, pada desain ini digambarkan pada desain input dan output. 


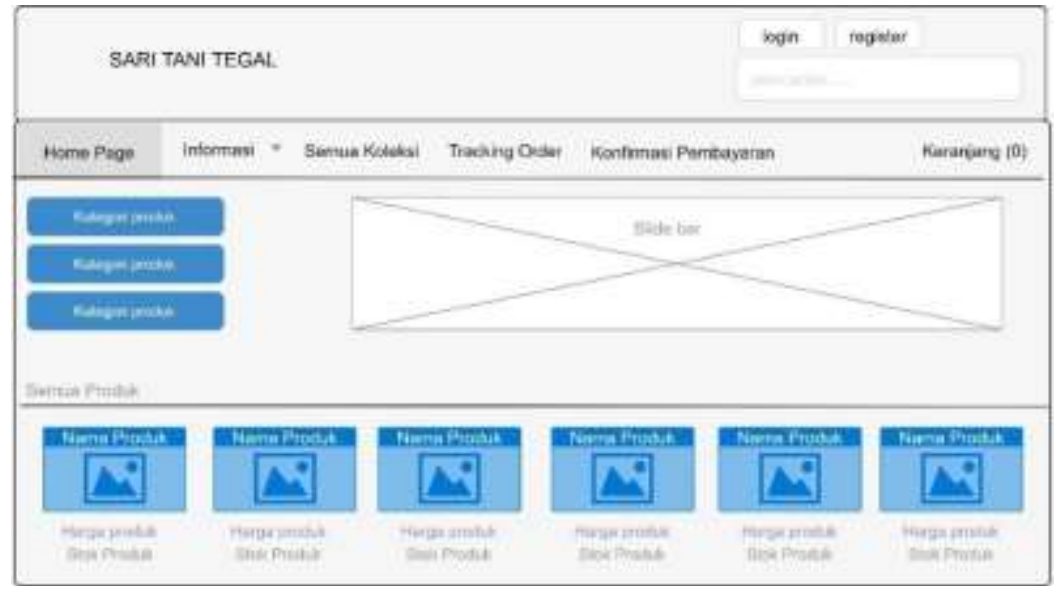

Gambar 4. Desain halaman utama pelanggan

Pada gambar 4 merupakan antar muka halaman utama pelanggan Toko Sari Tani Tegal. Dimana pada halaman tersebut pelanggan dalam melakukan transaksi sesuai apa yang akan dibeli. Pilihan pada halaman utama pelanggan diantaranya adalah melihat produk, pilihan untuk melakukan pemesanan produk, melakukan konfirmasi pembayaran, serta tracking order yang telah dilakukan.

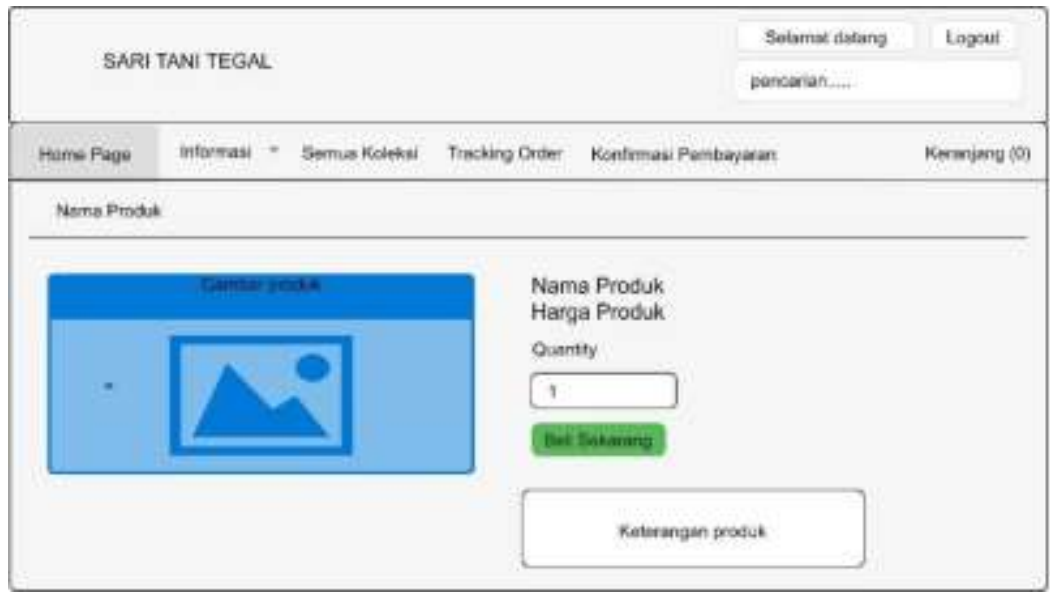

Gambar 5. Desain form pemesanan produk

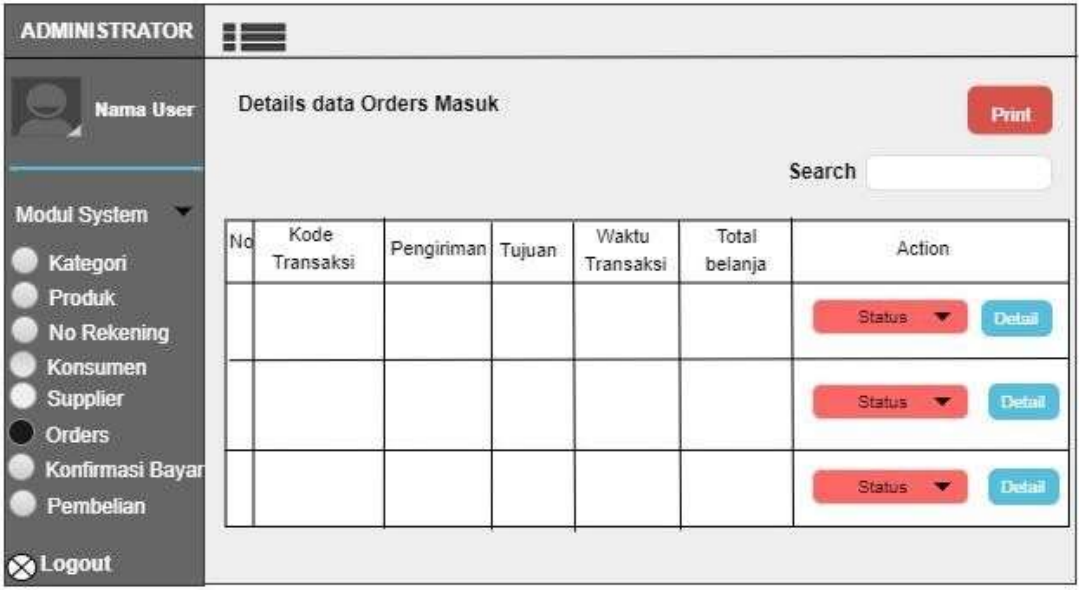

Gambar 6. Desain lihat orders 
Pada gambar 5 merupakan halaman form pemesanan produk yang diperuntukkan pelanggan. Pelanggan dapat menentukan jumlah barang sesuai produk yang akan dipesan. Dan gambar 6 merupakan halaman administrator, dimana seorang admin dapat melihat order dari pelanggan yang masuk. Dengan diketahui order masuk dan dilanjutkan dengan pengecekan pembayaran, maka langkah selanjutnya adalah penyiapan pengiriman barang.

\section{Implementasi}

Tahapan implementasi merupakan proses mewujudkan sistem berdasarkan tahapan yang telah dilakukan sebelumnya.

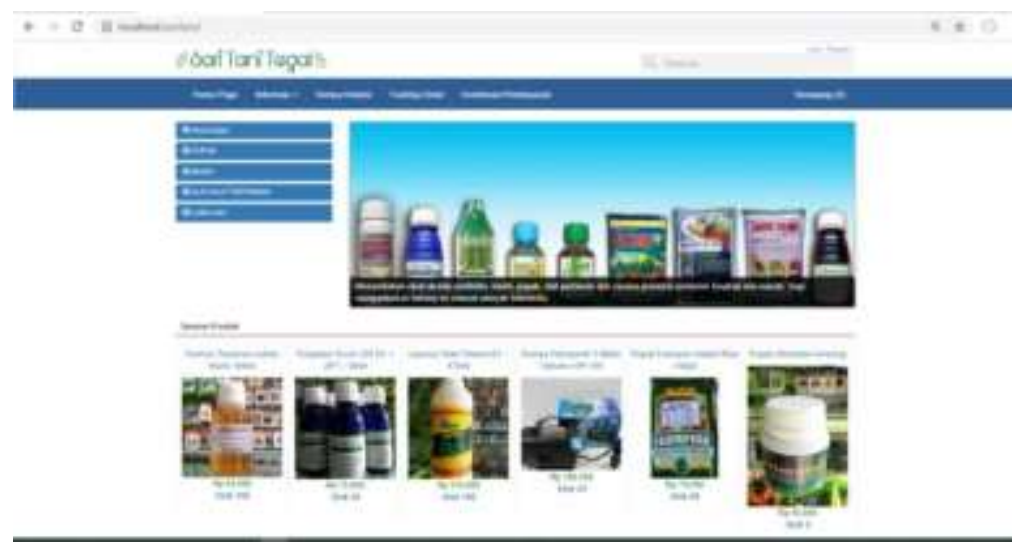

Gambar 7. Halaman utama pelanggan

Pada gambar 7. merupakan halaman implementasi dari sistem sehubungan dengan akses apa yang dapat dilakukan oleh pelanggan. Pelanggan memulai pemesanan produk melalui halaman ini.

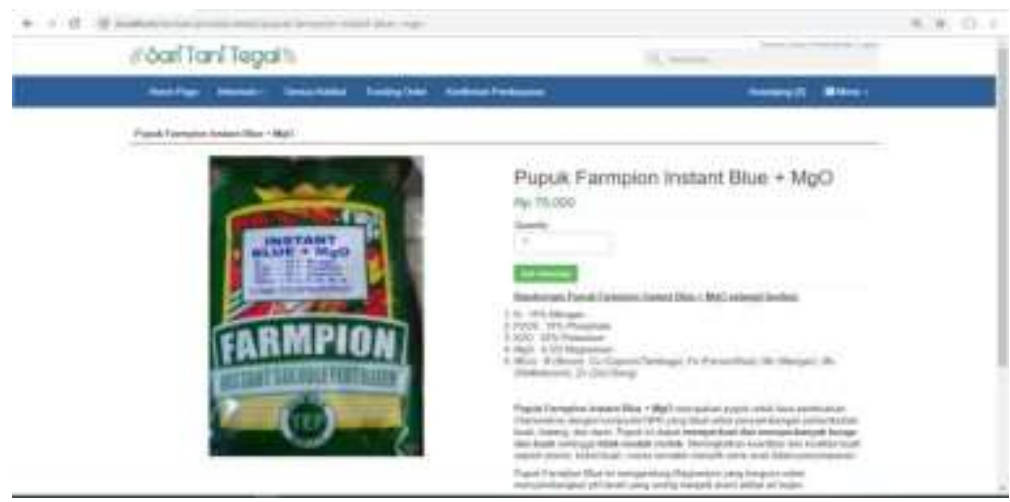

Gambar 8. Halaman pilih produk

Pada gambar 8. merupakan halaman implementasi dari sistem sehubungan dengan akses pelanggan terhadap sistem untuk memilih produk yang akan dipesan. Pada halaman ini produk dimunculkan lengkap dengan informasi produk yang disertai dengan gambar produk. 


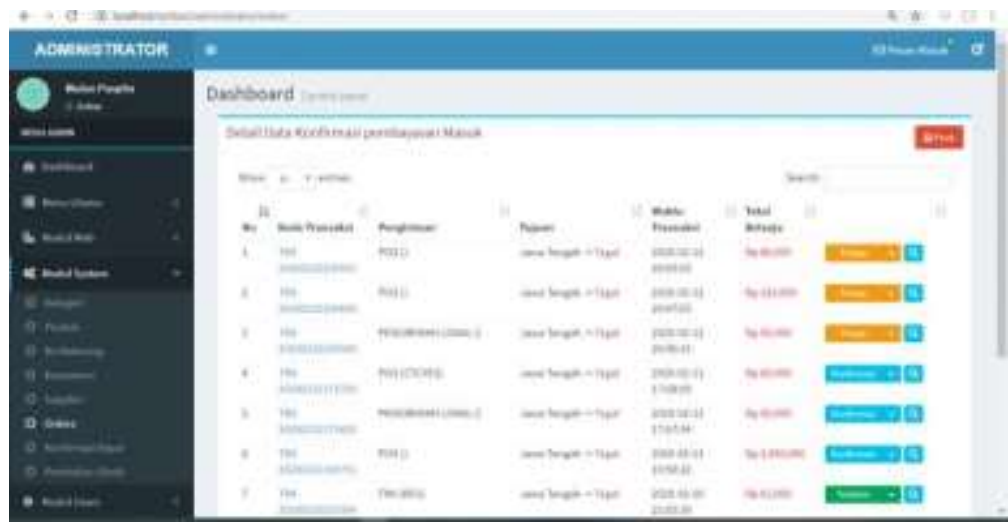

Gambar 9. Halaman kelola orders

Pada gambar 9. merupakan halaman implementasi dari sistem sehubungan dengan pengelolaan order penjualan yang masuk dari pelanggan. Melalui halaman ini proses penyiapan pesanan untuk segera dikirim dimulai.

\section{Pengujian}

Pada tahapan ini dilakukan dengan menggunakan black box dan white box testing. Pada black box testing dengan pengujian login, registrasi, check uot, kelola produk, kelola order, kelola data user, kelola data supplier dan melihat laporan order yang dapat disimpulkan bahwa hasil tersebut dapat berfungsi sebagai mana mestinya. Sedankan dalam pengujian white box menghasilkan flow graph, cyclomatic complexity, path independent dan test case. Tabel 1 berikut merupakan hasil pengujian white box dari Sistem Penjualan Online pada Toko Sari Tani Tegal

Tabel 1. Hasil pengujian white box

\begin{tabular}{lcccc}
\hline Fitur & $\begin{array}{c}\text { Cyclomatic } \\
\text { Complexity }\end{array}$ & $\begin{array}{l}\text { Path } \\
\text { Independent }\end{array}$ & $\begin{array}{l}\text { Test } \\
\text { Case }\end{array}$ & Hasil \\
\hline Login & 2 & 2 & 2 & Valid \\
Tambah Supplier & 2 & 2 & 2 & Valid \\
Edit Supplier & 2 & 2 & 2 & Valid \\
Tambah Produk & 3 & 3 & 3 & Valid \\
Hapus Produk & 1 & 1 & 1 & Valid \\
\hline
\end{tabular}

\subsection{Deployment}

Tahap ini menampilkan hasil evaluasi dari aplikasi web penjualan online Toko Sari Tani terhadap pengguna akhir yaitu pelanggan. Untuk mengetahui hasilnya dilakukan evaluasi tersebut dengan melakukan uji coba ke beberapa pengguna dengan menggunakan data sementara. Berikut pada tabel 2 merupakan hasil dari evaluasi pada aplikasi web penjualan online Toko Sari Tani :

Tabel 2. Evaluasi sistem

\begin{tabular}{lll}
\hline \multicolumn{1}{c}{ Fitur } & \multicolumn{1}{c}{ Pengamatan } & Hasil \\
\hline Login & $\begin{array}{l}\text { Berhasil masuk ke dalam sistem penjualan online } \\
\text { sebagai member konsumen } \\
\text { Registrasi }\end{array}$ & $\begin{array}{l}\text { Terpenuhi } \\
\text { pada form registrasi }\end{array}$ \\
Kelola Profile & $\begin{array}{l}\text { Berhasil melakukan kelola profile seperti melihat } \\
\text { profile dan mengupdate profile }\end{array}$ & Terpenuhi \\
Checkout & $\begin{array}{l}\text { Berhasil melakukan pemesanan produk } \\
\text { Konfirmasi Bayar }\end{array}$ & Berhasil melakukan konfirmasi bayar dengan \\
\hline
\end{tabular}




\begin{tabular}{lll}
\hline & menginputkan data-data pada form konfirmasi & \\
Tracking Order & Berhasil melihat status pesanan & Terpenuhi \\
Lihat Informasi & Berhasil melihat informasi yang & Terpenuhi \\
& ada dalam sistem berupa informasi & \\
& tentang toko, informasi cara & \\
& berbelanja, serta informasi berita & \\
\hline
\end{tabular}

\section{KESIMPULAN}

Proses pembuatan sistem informasi penjualan yang berbasis web di Toko Sari Tani Tegal ini dapat ditarik beberapa bahwa Sistem informasi penjualan ini dapat menjadikan kemudahan buat para pelanggan saat melakukan transaksi pemesanan produk yang dapat dilakutan tidak harus datang ke Toko. Sistem yang dibuat dapat membantu pemilik usaha dalam proses penyimpanan data, pencarian data, dan pembaruan data yang dibutuhkan. Sistem yang dibuat dapat memperkecil kemungkinan adanya kesalahan dalam pencatatan transaksi data. Dengan dibuatnya sistem ini maka mempermudah pemilik usaha dalam pembuatan laporan- laporan seperti laporan produk, laporan pendapatam, laporan orders secara cepat, detail dan tepat.

\section{SARAN}

Adapaun saran untuk kedepannya, website ini dikembangkan dengan menambahkan fitur-fitur yang lebih lengkap. Stok barang perlu dikunci dalam waktu pembayaran yang terterta, agar pembeli tidak kehabisan stok jika belum melakukan pembayaran. Perlu adanya backup data yang dilakukan, karena tidak menutup kemungkinan adanya kehilangan data atau adanya kerusakan terharap hardware maupun software. Perlu melakukan maintenance secara berkala agar dapat mengetahui apakah sistem tersebut dapat bejalan sesuai dengan yang diingikan.

\section{DAFTAR PUSTAKA}

[1] R. R. Sani, I. B. Fachreza dan F. E. Nilawati, "Perancangan E-commerce Pada Produk Wingko Babat Pak Moel Berbasis Web," JOINS (Journal of Information System), vol. 3, no. 2, pp. 151-160, 2018.

[2] A. S. Puspasari dan H. Sunardi, "Sistem Informasi Penjualan Pupuk Berbasis Web pada PT. Sri Aneka Karyatama," Jurnal Media Infotama, vol. 14, no. 1, pp. 1-6, 2018.

[3] Ummasyroh, Y. Herawati dan A. Furqon, "Perancangan Aplikasi Sistem Informasi Penjualan Berbasis Microsoft Access 2007 pada Toko Syafa Collection," Media Mahardhika, vol. 13, no. 1, pp. 79-97, 2014.

[4] R. S. Pressman dan B. R. Maxim, Software engineering : apractitioner's approach, 8th penyunt., New York: McGraw-Hill Education, 2015.

[5] F. Sullyanto, K. Ghazali dan S. , "Sistem Informasi Pemesanan Seragam Sekolah Pada CV. Lima Saudara Palembang Berbasis Web," Jurnal Ilmiah Informatika Global, vol. 8, no. 2, pp. 49-53, 2017.

[6] A. Widodo dan S. , "Sistem Informasi Penjualan Barang Berbasis Web Pada CV. Laboindo Intimedika Semarang," JOINS (Journal of Information System), vol. 2, no. 1, pp. 88-99, 2017.

[7] R. A. Sukamto dan M. Shalahuddin, Rekayasa Perangkat Lunak Struktur dan Berorientasi Objek., Bandung: Informatika, 2014. 